\title{
Dyslipoproteinemia in Chronic HCV Infection
}

\author{
Yoshio Aizawa, Hiroshi Abe, Kai Yoshizawa, Haruya Ishiguro, \\ Yuta Aida, Noritomo Shimada and Akihito Tsubota
}

Additional information is available at the end of the chapter

http://dx.doi.org/10.5772/48117

\section{Introduction}

Hepatitis C virus (HCV) is a unique virus whose life cycle is closely associated with lipoprotein metabolism [1, 2,3]. Assembly of HCV particles, formation of HCV-virions, is closely connected to the formation of lipid droplets in hepatic cells that may serve as an assembly platform $[1,4]$. In addition, the production of $\mathrm{HCV}$ particles is tightly linked to the very low-density lipoprotein (VLDL) production pathway [5, 6]. HCV particles circulating in the blood during chronic HCV infection form lipo-viral particles (LVP) that are rich in triglycerides (TG), apoB-100 and apoE, with physiochemical similarity to VLDL particles and are highly infectious [7, 8]. In contrast, denser HCV particles are less infectious. These data strongly suggest that both viral particles and VLDL are integral components of LVPs with high infective capability. Although LVPs are thought to be assembled in liver cells by association with host lipoproteins prior to secretion, association between HCV and VLDL in the circulation after secretion from the liver cannot be ruled out.

Studies to date have indicated that the process of HCV assembly and secretion largely utilizes the VLDL pathway. Therefore, suppression of apoB-100 or apoE also inhibits secretion of $\mathrm{HCV}$. Inhibition of microsomal triglyceride transfer protein (MTP), a critical protein for the initial step of VLDL assembly by co-translational lipidation of apoB-100 [9, 10], inhibits HCV secretion.

As HCV depends on VLDL pathways for its assembly and secretion, the lipid-rich environment of the liver cell combined with reduced VLDL secretion may be required for efficient assembly and secretion of HCV virions by ensuring the feasibility of co-assembly with VLDL. Hypobetalipoproteinemia, reduced activity of MTP with negative correlation to hepatic steatosis and viral load, is observed in HCV-G3 chronic infection [11]. Secretion of apoB-100 was reduced by HCV nonstructural proteins using the HCV subgenomic replicon expression system and interaction between the HCV NS5A and apoB-100 was observed [12]. 
In addition, there has been accumulating evidence that the HCV core protein is induced upon the redistribution of lipid droplets, affecting the assembly of both HCV and VLDL [13, 14]. The function of core protein in lipid metabolism has been widely examined including in models of steatosis involving HCV core protein transgenic mice [15]. Findings include reduction in activity of MTP [9] and Tyr164Phe substitution in relation to marked steatosis in HCV-G3 infection [16]. Although the participation of Arg70Gln/His substitution in steatosis of hepatocytes has been proposed [17], the precise connection between hepatic steatosis and HCV-G1b and/or HCV-G2 infection remains unclear.

As mentioned earlier, HCV particles in peripheral blood may associate not only with VLDL, but also with other lipoproteins, especially LDL, since circulating LVPs span a wide range of buoyant gravity and physicochemical characteristics [8, 18]. The association of lipoproteins with $\mathrm{HCV}$ particles may be beneficial for $\mathrm{HCV}$ through protection against anti-HCV neutralizing antibodies, as the antigenicity of $\mathrm{HCV}$ surface proteins is hidden beneath the associated lipoprotein particle [18]. Lipoprotein particles isolated from sera of HCV patients displayed differentially modulated lipid synthesis in human monocyte-derived macrophages in comparison to lipoproteins obtained from normal subjects, suggesting that HCV infection influences the biochemical composition of lipoproteins, thus revealing an alternative influence on lipid metabolism [19]. HCV entry into liver cells may occur through many receptors, including CD81 (direct binding to HCV E2 protein) and claudin-1, both of which act during the later steps of HCV entry [20]. The predominant role of LDL-receptors or remnant receptors is to catch VLDL-derived lipoprotein particles. Meanwhile, SR-BI (a receptor for HDL and oxidized LDL) directly binds HCV E2 protein [21]. Very recently, Nieman-Pick C1-like 1 cholesterol absorption receptor has been reported as a new factor for HCV entry to hepatic cells [22]. Interestingly, lipoprotein lipase, which hydrolyzes VLDL, is reported to increase the binding of LVP to hepatic cells while simultaneously decreasing infection levels of hepatic cells [23].

These findings suggest that examination of serum lipid profiles in chronic HCV infection may be important for understanding the biological features of HCV infection. Compared to normal subjects, low levels of TC, high-density lipoprotein cholesterol (HDL-C) and LDL-C was reported in chronic HCV-G3a infection [24]. However, lipoprotein profiles in infections of genotypes other than HCV-G3 have not been fully described and the data are somewhat conflicted. Moriya et al. indicated that TC levels and apoB, CII and CIII were reduced in HCV-G1b compared with chronic HCV-G2a or hepatitis B virus (HBV) infection [25], while others have not reported such a distinction. In addition, distortion of serum lipid levels has been widely observed in connection with virological outcome of IFN-based antiviral therapy, especially in HCV-G1 infection. Lower LDL-C, HDL-C, TC and/or TG was reported to be a possible predictor for unfavorable response to IFN-based therapy [24, 26, 27]. However, after the discovery of a genetic polymorphism near the human IL28B gene as the most potent predictor of the outcome of IFN-based therapy, the distortion of serum lipid levels is no longer thought to be an independent factor, but rather a confounding variable for predicting therapeutic efficacy [28].

In this chapter, we described the lipoprotein profiles in chronic HCV-G1b infection (the most common genotype in Japan) compared with that in chronic HCV-G2 infection (the second most common genotype in Japan). In addition, the influence of the genetic 
polymorphism near the human IL28B gene and aa substitutions in the core and NS5A regions of $\mathrm{HCV}$ on lipoprotein profiles in chronic HCV-G1b infection was determined.

To examine the serum lipid profiles of many patients, ultracentrifugation was unsuitable. We instead measured serum lipoprotein using HPLC in addition to a conventional laboratory method involving measurement of apolipoproteins. To examine serum LDL-C levels, the Friedwald equation can be used as an indirect calculation method yielding "total cholesterol minus HDL-C minus $0.2 \times$ TG. However, the precision of this equation has not been determined in pathological conditions such as chronic HCV infection.

\section{Methods}

\subsection{Patients and materials}

Fasting sera of patients who were diagnosed as having chronic HCV infection were collected and stored at lower than -30 degrees centigrade until examination of apolipoproteins and/or lipoproteins. At the time of serum collection, TC, TG and HDL-C were measured using a routine laboratory kit. Serum LDL-C was measured by a direct assay using an LDL-cholesterol kit (Sekisui Medical, Japan). A good correlation between the direct assay and indirect measurement using the Friedwald equation $(r=0.96)$ in 96 healthy adults whose TG level was lower than $400 \mathrm{mg} / \mathrm{dl}$ was observed.

Detection of HCV infection was made using a commercial real-time PCR Kit. Detection of $\mathrm{HCV}$ genotype was performed by a PCR method based on the $5^{\prime}$ non-coding sequence. Some patients diagnosed as having HCV-G1b infection, aa substitutions at core 70/91, interferon sensitivity determined region (ISDR) and/or IFN RBV resistance determining region (IRRDR) were examined. All patients examined were Japanese without ongoing treatment of IFN-based antiviral therapy.

All patients were confirmed not to be co-infected with HIV, HTLV, tuberculosis or other chronic bacterial infections. In addition, patients who were diagnosed with hepatic cirrhosis were excluded from the study. Study protocols were approved by the review board of each institution and written informed consent was obtained prior to study enrollment.

\subsection{Detection of serum apolipoproteins}

Serum levels of apolipoproteins (apoA1, apoA11, apoB, apoCII, apoCIII and apoE) were analyzed by immunonephelometry using an apolipoprotein detection kit (Sekisui Medical, Japan). Serum apoB-48 was assayed by chemiluminescent enzyme immunoassay [29] using an apoB-48 CLEIA kit (Fujirebio, Japan). Serum apoB-100 level was determined as apoB minus apoB-48.

\subsection{Detection of lipoprotein fractions by HPLC based method}

Fasting serum lipoprotein profiles were analyzed using an HPLC system with on-line enzymatic dual detection of cholesterol and TG as described previously (LipoSEARCH, Skylight Biotech, Japan) [30]. Briefly, $10 \mu \mathrm{l}$ of whole serum sample was injected into two 
connected columns $(300 \times 7.8 \mathrm{~mm})$ of TSKgel LipopropakXL (Tosoh, Japan) and eluted by TSKeluent Lp-1 (Tosoh). The eluent from the columns was divided by a micro splitter and continuously monitored at $550 \mathrm{~nm}$ after an online enzymatic reaction with a commercial kit, Determiner L TC (Kyowa Medex, Japan) and Determiner L TG (Kyowa Medex). Then, the cholesterol and TG concentrations were calculated by the computer program, which was designed to process complex chromatograms with a modified Gaussian curve fitting for resolving overlapping peaks by mathematical treatment.

Lipoprotein particles were fractionated into four major lipoproteins according to particle diameter as follows: $>80 \mathrm{~nm}$ classified as chylomicrons; 30 to $80 \mathrm{~nm}$ as VLDL; 16 to $30 \mathrm{~nm}$ as LDL; and 8 to $16 \mathrm{~nm}$ as HDL. Next, the concentration of cholesterol and TG was measured in each major lipoprotein fraction and the ratio of cholesterol:TG concentration (C:T ratio) was calculated. This system has been successfully applied elsewhere in clinical research with excellent reproducibility [31]. Although freezing and thawing may affect the lipoprotein fraction, the influence of freezing and thawing on the measurement of cholesterol and TG concentration in healthy samples is fairly low, as described on homepage of Skylight Biotech (http://www.lipo-search.com).

Figure 1 illustrates chromatographic pattern of cholesterol and triglycerides derived LipoSEARCH was illustrated.

\section{Cholesterol concentration}

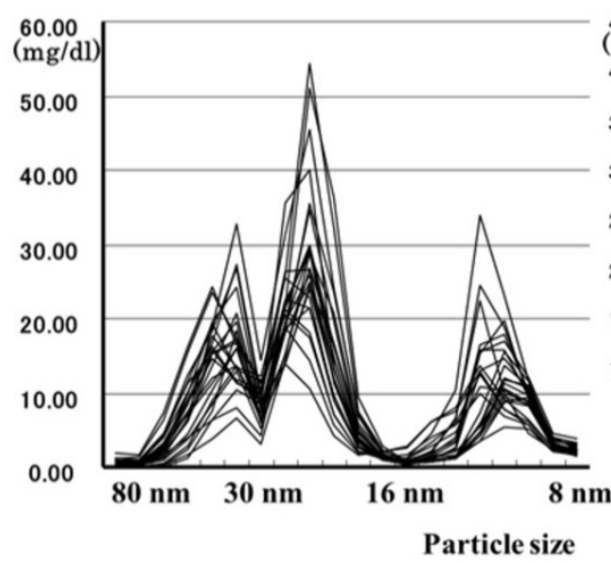

\section{TG concentration}

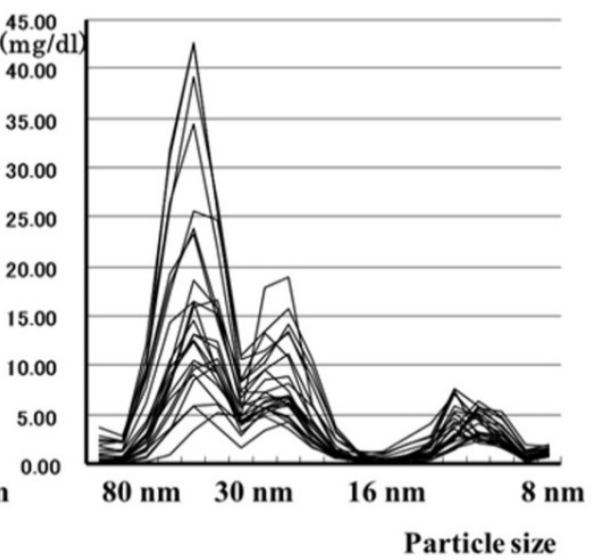

Figure 1. Chromatographic pattern of fasting serum cholesterol and TG derived HPLC-based method (LipoSEARCH).

\subsection{Detection of amino acid substitutions at aa 70/91 in core region of $\mathrm{HCV}-\mathrm{G} 1 \mathrm{~b}$}

HCV RNA was extracted from serum samples and reverse transcribed with random primers and MMLV reverse transcriptase (Takara Shuzo, Japan). Based on the method of Akuta et al. [32], nucleotide sequences of the core region were analyzed by direct sequencing after nested PCR. Subsequently, the aa substitutions at position 70 (arginine, Arg70; or glutamine/histidine, Gln70/His70) and at position 91 (leucine, Leu91; or methionine Met91) were determined. 


\subsection{Detection of amino acid substitutions related to ISDR in NS5A of HCV-G1b}

Nucleotide sequences of NS5A-ISDR were analyzed by direct sequencing after doubleround PCR according to Enomoto et al. [33]. Then, the aa sequence from 2209-2248, termed the ISDR region, in NS5A was determined and the numbers of aa substitutions defined.

\subsection{Detection of amino acid substitutions related to IRRDR in NS5A of HCV- G1b}

Nucleotide sequences of NS5A-IRRDR were analyzed by direct sequencing after doubleround PCR according to El-Shamy et al. [34] and the numbers of aa substitutions within this region (2334-2376) determined. Moreover, the particular position of aa substitutions were evaluated in connection to dyslipoproteinemia, found in chronic HCV-G1b patients.

\section{Results}

Difference in lipoprotein profiles between patients with chronic HCV-G2 and HCV-G1b infection, between HCV-G1b patients with favorable and unfavorable response to PEG-IFN plus RBV combination therapy, and between minor (non-responder) genotypes and major (responder) genotypes of IL28B (rs8099917)

Serum lipoprotein profiles are clearly distorted in patients with chronic HCV-G3 infection and this is characterized by a decrease in apoB-100-related cholesterol [24]. However, serum lipoprotein disturbances in other genotypes are an issue that has been under discussion. In addition, disturbances in lipoprotein profiles have been reported in patients who were not responsive to IFN-based antiviral therapy in comparison to responsive patients with chronic HCV-G1 infection [26, 27]. However, whether or not dyslipoproteinemia is an independent factor affecting the efficacy of IFN-based therapy remains controversial. The latest interpretation seems to be that dyslipoproteinemia in HCV-G1 patients may be a confounding factor of the host genotype of IL28B that is the strongest predictor for virological outcome following PEG-IFN plus RBV therapy [28].

Initially, we compared serum levels of apolipoproteins in chronically HCV-G2- and G1binfected patients paying special attention to virological outcome of PEG-IFN plus RBV therapy in the HCV-G1b patients. Of the pre-treatment fasting sera taken from $42 \mathrm{HCV}-\mathrm{G} 1 \mathrm{~b}$ patients, 23 achieved a sustained viral response (SVR; negative for HCV RNA at 6 months after standard 48 weeks of therapy); 8 had a transient viral response (TVR; HCV RNAnegative during therapy, but reappearing after therapy); and 11 had a non-viral response (NVR; HCV RNA-positive during therapy). $24 \mathrm{HCV}-\mathrm{G} 2$ patients were also examined.

There were no differences in the concentration of apoAI, apoAII, apoCIII, apoE and apoB-48 $(138.2 \pm 27.4 \mathrm{mg} / \mathrm{dl}$ vs. $142.4 \pm 32.4 \mathrm{mg} / \mathrm{dl}, 30.4 \pm 6.5 \mathrm{mg} / \mathrm{dl}$ vs. $29.9 \pm 4.8 \mathrm{mg} / \mathrm{dl}, 5.7 \pm 2.0 \mathrm{mg} / \mathrm{dl}$ vs. $6.2 \pm 2.4 \mathrm{mg} / \mathrm{dl}, 4.4 \pm 1.1 \mathrm{mg} / \mathrm{dl}$ vs. $4.3 \pm 1.0 \mathrm{mg} / \mathrm{dl}$ and $3.3 \pm 4.2 \mathrm{mg} / \mathrm{dl} \mathrm{vs.} 3.1 \pm 1.4 \mathrm{mg} / \mathrm{dl}$, respectively) between HCV-G1b and G2 patients. In addition, no significant changes were observed among patients with HCV-G1b showing different outcome of PEG-IFN plus RBV therapy. However, there were substantial differences in apoB and apoCII levels according to the response to PEG- 
IFN plus RBV therapy in HCV-G1b patients. In HCV-G1b infection, apoB and apoCII levels were significantly higher in SVR patients than in NVR patients. The levels of apoB and apoCII in HCV-G2 patients were similar to those in HCV-G1b patients who achieved SVR (Figure 2).

These data suggest that the apolipoprotein profile in HCV-G1b patients is basically indistinguishable from that in HCV-G2 patients. Meanwhile, the profile differed in relation to different outcomes of PEG-IFN plus RBV therapy among chronic HCV-G1b infection. From these observations, we presumed that a decrease in LDL and/or VLDL may be a feature of dyslipoproteinemia in HCV-G1b patients who failed to respond to PEG-IFN plus RBV therapy. ApoB-100 (about $95 \%$ of apoB is apoB-100 in fasting sera) is an indicator of total VLDL, intermediate-density lipoprotein (IDL) and LDL particles in the blood because each particle of VLDL, IDL or LDL is composed of one molecule of apoB-100. Moreover, the majority of apoCII, which activates the enzyme lipoprotein lipase in capillaries, is associated with VLDL. Therefore, a decrease in apoCII could be related to a decrease in VLDL. Taking into consideration these observations, we concluded that a characteristic of the lipoprotein profile during the pre-treatment period of chronic HCV-G1b patients who subsequently fail antiviral IFN-based therapy is a decline in VLDL levels. Although lower serum apoE has recently been reported to be related to a favorable response to IFN-based therapy [35], we did not find any differences in serum apoE levels.

ApoB concentration

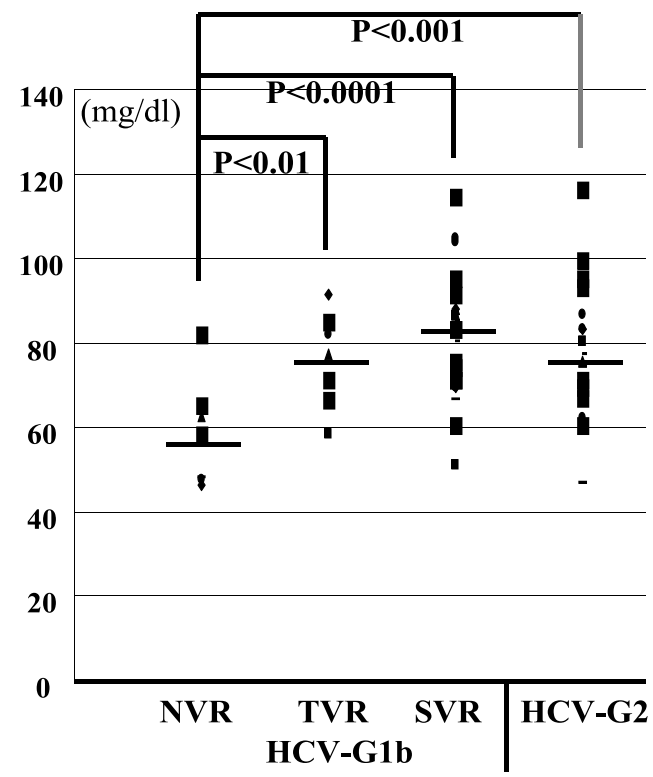

\section{ApoCII concentration}

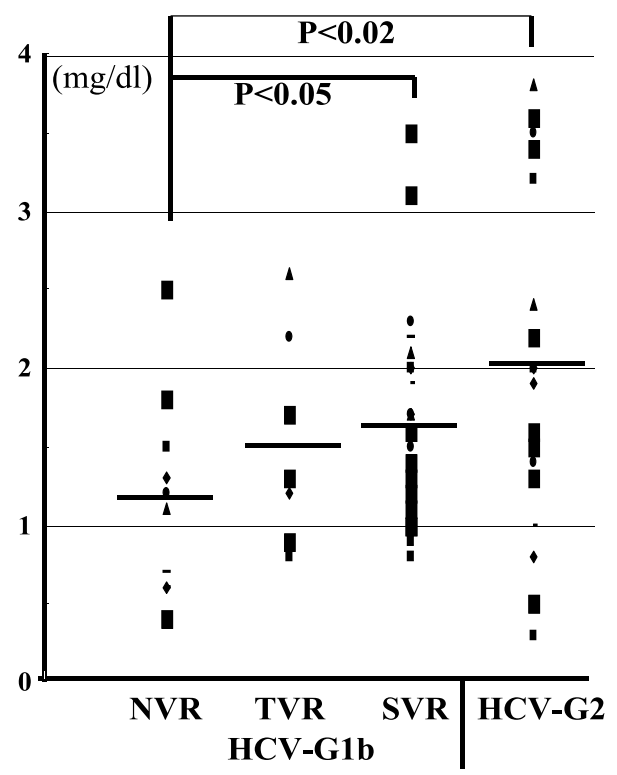

Figure 2. Serum apoB and apoCII levels in patients with chronic HCV-G1b or HCV-G2 infection. All HCV-G1b patients were treated with standard PEG-IFN plus RBV combination therapy and clarified according to the virological response. (NVR; non-viral response, TVR; transient viral response, SVR; sustained viral response) 
Next, we examined the profiles of serum lipoproteins in 32 patients who were chronically infected with HCV-G2 and 111 patients with HCV-G1b, along with genotyping of the region near the IL28B gene (SNP ID rs8099917), the strongest predictor of outcome to PEG-IFN plus RBV therapy. Recently, we reported that serum apoB-100 levels are prescribed by genetic polymorphism of rs8099917, and a minor genotype of rs8099917 (TG or GG; also known as non-responder genotype of PEG-IFN plus RBV combination therapy) may be related to a decrease in serum apoB-100 in chronic HCV-G1b infection [36]. In chronic HCV-G1b infections in Japan, the minor genotype was found in $25-35 \%$ of cases, whereas it was only $10-20 \%$ in chronic HCV-G2 infections. We examined SNP of rs8099917 and the lipoprotein profiles obtained by LipoSEARCH were compared among $29 \mathrm{HCV}-\mathrm{G} 2$ patients who had the major genotype of IL28B (rs8099917), $75 \mathrm{HCV}-\mathrm{G} 1 \mathrm{~b}$ patients who had the major IL28B genotype and $36 \mathrm{HCV}-\mathrm{G} 1 \mathrm{~b}$ patients who had the minor IL28B genotype.

There were no differences related to gender, age, fibrosis score of liver biopsy, BMI, serum ALT level, viral load or platelet count among these three groups (data not shown). We did not cite the chylomicron fraction because this fraction was too small to analyze precisely.

\begin{tabular}{|l|c|c|c|c|}
\hline \multicolumn{1}{|c|}{ Lipoprotein fraction } & TC & VLDL-C & LDL-C & HDL-C \\
\hline HCV-G2, IL28B major & $167.92 \pm 31.20$ & $38.22 \pm 17.65$ & $81.18 \pm 22.25$ & $44.79 \pm 14.49$ \\
\hline HCV-G1b, IL28B major & $169.65 \pm 30.52$ & $45.52 \pm 18.64$ & $72.80 \pm 17.27^{*}$ & $46.54 \pm 12.22$ \\
\hline HCV-G1b, IL28B minor & $161.69 \pm 30.87$ & $36.22 \pm 15.18^{* * *}$ & $68.61 \pm 18.40^{*}$ & $52.20 \pm 16.64^{* *}$ \\
\hline
\end{tabular}

$(\mathrm{mg} / \mathrm{dl})$

\begin{tabular}{|l|c|c|c|c|}
\hline \multicolumn{1}{|c|}{ Lipoprotein fraction } & TG & VLDL-TG & LDL-TG & HDL-TG \\
\hline HCV-G2, IL28B major & $104.46 \pm 59.41$ & $52.48 \pm 36.43$ & $27.22 \pm 10.17$ & $16.22 \pm 5.91$ \\
\hline HCV-G1b, IL28B major & $93.30 \pm 36.74$ & $43.52 \pm 20.99$ & $24.65 \pm 7.37$ & $16.82 \pm 6.20$ \\
\hline HCV-G1b, IL28B minor & $92.92 \pm 42.21$ & $41.53 \pm 20.32$ & $22.10 \pm 6.69^{*}$ & $19.14 \pm 8.25$ \\
\hline
\end{tabular}

${ }^{*} P>0.05$ vs HCV-G2, ${ }^{* *} P>0.05$ vs HCV-G1b with IL28B major, ${ }^{* * *} P>0.01$ vs HCV-G1b with IL28B major

Table 1. Differences in lipoprotein fractions among patients with chronic HCV-G1b and G2 infection with different IL28 genotype

In patients with HCV-G1b having the IL28B major (responder) genotype, the concentration of cholesterol in the LDL fraction (LDL-C) was significantly lower than that in patients with HCV-G2. In addition, the tendency of a reciprocal increase of VLDL-C $(P=0.055)$ in HCVG1b patients having the responder genotype was observed. As a result, the level of LDL-C plus VLDL-C was similar between these two groups. In contrast, a reciprocal increase of VLDL-C was not observed in G1b patients who had the non-responder genotype. Decrease of VLDL-C and increase of HDL-C is a feature of the non-responder genotype compared with the responder genotype in chronic $\mathrm{HCV}-\mathrm{G} 1 \mathrm{~b}$ patients.

We also examined serum lipoprotein profiles of five patients who had been infected with HCV-G1b, but achieved SVR by PEG-IFN plus RBV therapy (HCV-free status continuing for longer than 6 months). In these cured patients, low levels of VLDL-C and high levels of LDL-C and HDL-C were observed (Table 2). The lipoprotein profiles of these cured patients were quite normal with a normal composition of cholesterol and TG in each lipoprotein 
fraction when assessed by $\mathrm{C}: \mathrm{T}$ ratio. When compared with cured patients, a relative decrease of TG in the VLDL fraction and a relative increase of TG in the LDL and HDL fractions were noted in chronic HCV infection.

In chronic HCV infection, we unexpectedly found that the serum levels of LDL-C measured by an HPLC system (LipoSEARCH) were considerably lower than those measured directly using a conventional method (HCV-G1b: $93.8 \pm 26.76 \mathrm{mg} / \mathrm{dl}$; HCV-G2: $101.21 \pm 34.19 \mathrm{mg} / \mathrm{dl}$ ), or measured indirectly by the Friedwald equation. In place of the decreased LDL fraction, the VLDL fraction was increased. This pattern is somewhat reminiscent of hyperlipidemic (high TG) samples [31]. However, in chronic HCV infection, TG levels are not much different from those in cured patients. Therefore, this finding cannot be explained by an increase of TG.

\begin{tabular}{|l|c|c|c|c|}
\hline \multicolumn{1}{|c|}{ Lipoprotein fraction } & TC & VLDL-C & LDL-C & HDL-C \\
\hline $\begin{array}{l}\text { HCV-G1b, achieved } \\
\text { SVR }\end{array}$ & $177.49 \pm 35.63$ & $26.34 \pm 7.24$ & $89.41 \pm 31.61$ & $61.28 \pm 15.14$ \\
\hline
\end{tabular}

\begin{tabular}{|l|c|c|c|c|}
\hline & TG & VLDL-TG & LDL-TG & HDL-TG \\
\hline $\begin{array}{l}\text { HCV-G1b, achieved } \\
\text { SVR }\end{array}$ & $79.15 \pm 25.33$ & $44.11 \pm 18.77$ & $22.08 \pm 4.96$ & $10.47 \pm 2.64$ \\
\hline
\end{tabular}

$(\mathrm{mg} / \mathrm{dl})$

Table 2. Serum lipid profiles of patients who achieved SVR by PEG-IFN plus RBV therapy for chronic $\mathrm{HCV}-\mathrm{G} 1 \mathrm{~b}$ infection (sera were obtained at least 6 months after HCV was completely eradicated)

An increase of the VLDL fraction in chronic HCV infection could be explained by reduced enzymatic activity of lipoprotein lipase, which may facilitate HCV cell entry [23] while delaying the conversion of VLDL to LDL. Alternatively, discrepancy between chemically determined LDL (conventional measurement method) and levels determined by particle size (HPLC-based method) may be explained by the existence of LDL-associated LVPs in the blood during chronic HCV infection. These particles may have the physicochemical surface nature of LDLs, but particle sizes larger than $55 \mathrm{~nm}$ because the diameter of the HCV particle is about $55 \mathrm{~nm}$, and hence must be eluted in the VLDL fraction. Although we must take into consideration that lipoprotein particles could theoretically become fused together during freezing and thawing, thus seriously distorting the lipoprotein fraction pattern determined by the HPLC-based method, freezing and thawing has reportedly been found not to seriously affect lipoprotein profiles (Skylight Biotech, http://www.lipo-search.com).

A recent study by Nishimura et al. [37] suggested that diminished VLDL-TG/non-VLDL-TG is a key feature of chronic HCV infection. They detected VLDL-TG based on the chemical nature of VLDL. Their findings do not conflict with our data. Our results indicate a relative decrease of TG in the VLDL fraction, but a relative increase of TG in the LDL and HDL fractions. Thus, their findings of decreased VLDL-TG/non-VLDL-TG appear to be consistent with our results.

As this kind of lipid abnormality is not easily determined by conventional methodology, the HPLC-based method is extraordinarily useful for the study of lipoprotein profiles in chronic 
HCV infection. However, close attention to sample handling is needed because lipoprotein particles are fairly unstable.

The tentative conclusions are as follows: 1. Decrease of apoB (apoB-100) and apoB-100related cholesterol might be a main feature of dyslipoproteinemia in chronic HCV-G1b infection with unfavorable response to PEG-IFN plus RBV combination therapy; 2. Existence of abnormally large particles (LPVs) eluted in the VLDL fraction by HPLC, in spite of the chemical characteristics of LDL, and/or reduced activity of lipoprotein lipase with delayed VLDL dissociation, may be a feature of dyslipoproteinemia in chronic HCV infection; 3. Relative increase of TG in the LDL and HDL fractions with a relative decrease of TG in the VLDL fraction may be a feature of chronic HCV infection. These conclusions are partially in concordance with those reported by Mawatari et al. [38].

\section{Do viral factors participate in the dyslipoproteinemia seen during chronic HCV-G1b infection?}

HCV-G1 infection is widely distributed worldwide and the most common genotype in the world, while it is one of the most resistant genotypes to IFN-based therapy. In Japan, almost all G1 subtypes are $1 \mathrm{~b}$, contributing to more than $70 \%$ of chronic HCV infection cases. Viral factors participating in the response to IFN-based therapies have been extensively studied, especially with regard to HCV-G1b in Japan. Among them, core protein substitution at aa 70/91 [32] and aa substitutions in the ISDR [33], IRRDR [34] and in NS5A are widely accepted as candidates. Among them, substitution at core protein 91, Leu91Met, did not affect serum levels of apoB-100 as reported earlier by us [36]. We further examined the significance of substitution at aa 70, Arg70Gln/His, aa substitutions in the ISDR and IRRDR and aa substitutions at particular positions within the IRRDR.

In that former study, we determined that substitution of Arg70 to Gln/His70 was a distinctive factor participating in the regulation of serum apoB-100 levels in chronic HCVG1b patients, independent from the IL28B genotype. To clarify the lipoprotein profiles according to substitution at aa 70, we examined the lipoprotein profiles of fasting sera from 113 chronic HCV-G1b patients (68 were Arg70 and 45 were Gln/His70) by LipoSEARCH, as described earlier (Table 3).

\begin{tabular}{|c|c|c|c|c|}
\hline Lipoprotein fraction & TC & VLDL-C & LDL-C & HDL-C \\
\hline HCV-G1b $\quad$ Arg70 & $169.80 \pm 30.75$ & $43.16 \pm 18.39$ & $74.23 \pm 18.68$ & $48.09 \pm 14.03$ \\
\hline HCV-G1b Gln/His70 & $158.54 \pm 28.44$ & $40.02 \pm 17.40$ & $65.99 \pm 15.51^{*}$ & $47.57 \pm 14.09$ \\
\hline \multicolumn{5}{|r|}{$(\mathrm{mg} / \mathrm{dl})$} \\
\hline Lipoprotein fraction & TG & VLDL-TG & LDL-TG & HDL-TG \\
\hline HCV-G1b Arg70 & $89.49 \pm 33.68$ & $42.15 \pm 20.80$ & $23.53 \pm 6.71$ & $16.24 \pm 5.31$ \\
\hline HCV-G1b Gln/His70 & $95.95 \pm 41.99$ & $42.13 \pm 19.50$ & $18.14 \pm 7.83$ & $19.42 \pm 8.31^{*}$ \\
\hline
\end{tabular}

$(*: p>0.05)$

$(\mathrm{mg} / \mathrm{dl})$

Table 3. Differences in lipoprotein profiles related to the substitution at aa 70 in core region (Arg70 to $\mathrm{Gln} / \mathrm{His} 70$ ) in patients with chronic HCV-G1b infection 
There were no differences related to gender, age, fibrosis score of liver biopsy, BMI, serum ALT level, viral load or platelet count between Arg70 and Gln/His70. However, a significant difference was found in the distribution of the IL28B genotype (SNP of rs8099917). In Arg70, 49 patients were of the major (responder) genotype while 15 were of the minor (nonresponder) genotype. In Gln/His70, 22 were major and 20 were minor. A total of 7 patients remained undetermined. The difference in the IL28B genotype distribution between these two groups was significant ( $P=0.0005$ by chi-square test with Yate's correction). Therefore, the influence of the IL28B genotype was not excluded in this study. However, the pattern of dyslipoproteinemia seen in Gln/His70 cases is dissimilar to that in the IL28B minor genotype, which was described in detail. In core 70 mutants (Gln/His70), a significant decrease in LDL-C and increase in HDL-TG levels was demonstrated without a decrease in VLDL-C. TC levels tended to be lower than that in the core Arg70 cases ( $P=0.052)$. These findings may indicate that the core mutation at aa 70 is an important viral feature in relation to the dyslipoproteinemia seen in HCV-G1b, functioning mainly through decreasing LDL-C. As a result of the substitution at aa 70 , the nature of the amino acid is substantially changed. Therefore, the configuration and the biological activity of the core protein may be significantly disturbed, which may lead to the disruption of lipid metabolism. However, the precise mechanism of the consequence of aa 70 substitution on lipid metabolism is a matter to be solved in the future.

To exclude the influence of the IL28B genotype, we further compared the lipoprotein profiles in 49 patients with core 70 wild-type, and 22 patients with core 70 mutant phenotypes in whom the IL28B genotype was major (Table 4).

\begin{tabular}{|l|c|c|c|c|}
\hline Lipoprotein fraction & TC & VLDL-C & LDL-C & HDL-C \\
\hline HCV-G1b Arg70 & $173.37 \pm 30.83$ & $45.80 \pm 18.29$ & $76.41 \pm 18.28$ & $46.38 \pm 12.37$ \\
\hline HCV-G1b Gln/His70 & $155.44 \pm 24.13^{*}$ & $41.01 \pm 17.02$ & $65.71 \pm 13.34^{*}$ & $45.72 \pm 12.45$ \\
\hline
\end{tabular}

\begin{tabular}{|l|c|c|c|c|}
\hline \multicolumn{5}{|c|}{ (mg/dl) } \\
\hline HCV-G1b Arg70 & $92.33 \pm 35.95$ & $42.57 \pm 22.27$ & $25.50 \pm 6.77$ & $15.87 \pm 5.28$ \\
\hline HCV-G1b Gln/His70 & $93.44 \pm 36.33$ & $41.36 \pm 17.84$ & $26.12 \pm 8.72$ & $18.28 \pm 7.38$ \\
\hline
\end{tabular}

$\left({ }^{*}: p>0.05\right)$

$(\mathrm{mg} / \mathrm{dl})$

Table 4. Differences in lipoprotein profiles related to substitution at aa 70 in the core region (Arg70 to Glun/His70) in patients with chronic HCV-G1b having IL28B major (responder) genotype

Although a relatively small-sized study, the features of the dyslipoproteinemia seen in patients with the core aa 70 mutation was clearly elucidated as a decrease of TC due to a decrease of LDL-C. Even after exclusion of the influence of the IL28B genotype, the core 70 aa substitution was found to have a role in dyslipoproteinemia that may be critical.

We also examined aa substitutions in the NS5A region in relation to disturbance of serum lipid/lipoprotein levels, since NS protein may inhibit the secretion of apoB-100 in vitro [12]. Moreover, a polypeptide comprised of aa residues 2135 to 2419 within the NA5A protein coprecipitated with apoB, suggesting a possible interaction between NS5A protein and apoB- 
100. Thus, we examined aa substitutions in particular regions of NS5A to elucidate the possibility of a viral factor being the determinant of lipid metabolism. We compared the aa sequence 2209-2248 (ISDR) with the sequence of HCV-J and the number of aa substitutions was classified as wild-type ( 0 or 1$)$ or non-wild-type $(\geq 2)$. According to the numbers of aa substitutions in the ISDR [33], 102 of 117 subjects were judged to be wild-type and 15 nonwild-type. No significant differences in serum apoB and lipid concentrations were found between wild-type and non-wild-type ISDR (Table 5).

\begin{tabular}{|c|c|c|c|c|}
\hline Lipid profile & T.C. & TG & LDL-C ${ }^{*}$ & apoB \\
\hline ISDR wild & $172.8 \pm 32.0$ & $104.3 \pm 54.1$ & $92.5 \pm 26.6$ & $80.9 \pm 19.8$ \\
\hline ISDR non-wild & $167.1 \pm 28.0$ & $82.2 \pm 26.2$ & $92 . .9 \pm 22.1$ & $78.2 \pm 13.9$ \\
\hline
\end{tabular}

$(\mathrm{mg} / \mathrm{dl})$

*measured directly using commercial kit. Note the substantial differences of LDL-C level measured by HPLC system shown in Table 1, Table 2 and Table 3.

Table 5. Lipid profiles of HCV-G1b patients with ISDR wild and ISDR non-wild

Although not described in Table 5, there was no statistical difference between patients with wild-type and non-wild-type ISDR in terms of serum levels of apoAI, apoAII, apoCII, apoCIII, apoE and apoB-48. We also compared lipid profiles between patients with a substitution number of $0(\mathrm{~N}=80)$ and $\geq 1(\mathrm{~N}=37)$, and found no significant difference (data not shown).

We very recently examined the aa substitution number and the place of substitution in the IRRDR (aa 2334-2376) in 105 patients who were chronically infected with HCV-G1b. By comparison with the HCV-J sequence, the number of aa substitutions was determined. A high degree ( $\geq 6$ substitutions) of sequence variation in the IRRDR, which is thought to be a useful marker for predicting SVR [34], was found in 34 patients, whereas a less diverse $(\leq 5$ substitutions) IRRDR sequence (predictive of non-SVR) was found in 71 patients.

The clinical background is illustrated in Table 6 .

\begin{tabular}{|l|l|l|l|}
\hline Gender $(\mathrm{M} / \mathrm{F})$ & $42 / 63$ & TG & $89.8 \pm 40.2(\mathrm{mg} / \mathrm{dl})$ \\
\hline Age & $62.9 \pm 12.0($ years $)$ & LDL-C & $95.5 \pm 29.2(\mathrm{mg} / \mathrm{dl})$ \\
\hline ALT & $53.5 \pm 38.5(\mathrm{U} / \mathrm{L})$ & apoB-100 & $73.0 \pm 21.1(\mathrm{mg} / \mathrm{dl})$ \\
\hline Albumin & $4.1 \pm 0.4(\mathrm{~g} / \mathrm{dl})$ & rs8099917 (Major/Minor) & $65 / 40$ \\
\hline Plt & $16.0 \pm 6.3 \times 10^{4}$ & aa 70 (Wild/Mutant) & $64 / 41$ \\
\hline HCV-RNA & $6.4 \pm 0.6(\log / \mathrm{m} / \mathrm{ml})$ & aa 91 (Wild/Mutant) & $63 / 42$ \\
\hline TC & $171.3 \pm 32.7(\mathrm{mg} / \mathrm{dl})$ & ISDR (Wild / Mutant) & $92 / 12$ \\
\hline
\end{tabular}

Table 6. Clinical characteristics of $105 \mathrm{HCV}-\mathrm{G} 1 \mathrm{~b}$ patients whose IRRDR sequences were examined

The number of aa substitution detected in this study was illustrated in Figure 3.

As shown in Figure 3, the substitution number in the IRRDR was widely distributed. There was no difference in lipid profile between the two groups (substitution number $\geq 6$ vs. substitution number $\leq 5$ ) along with other clinical backgrounds except for the distribution of the IL28B genotype (Table 7). 
Number of patient

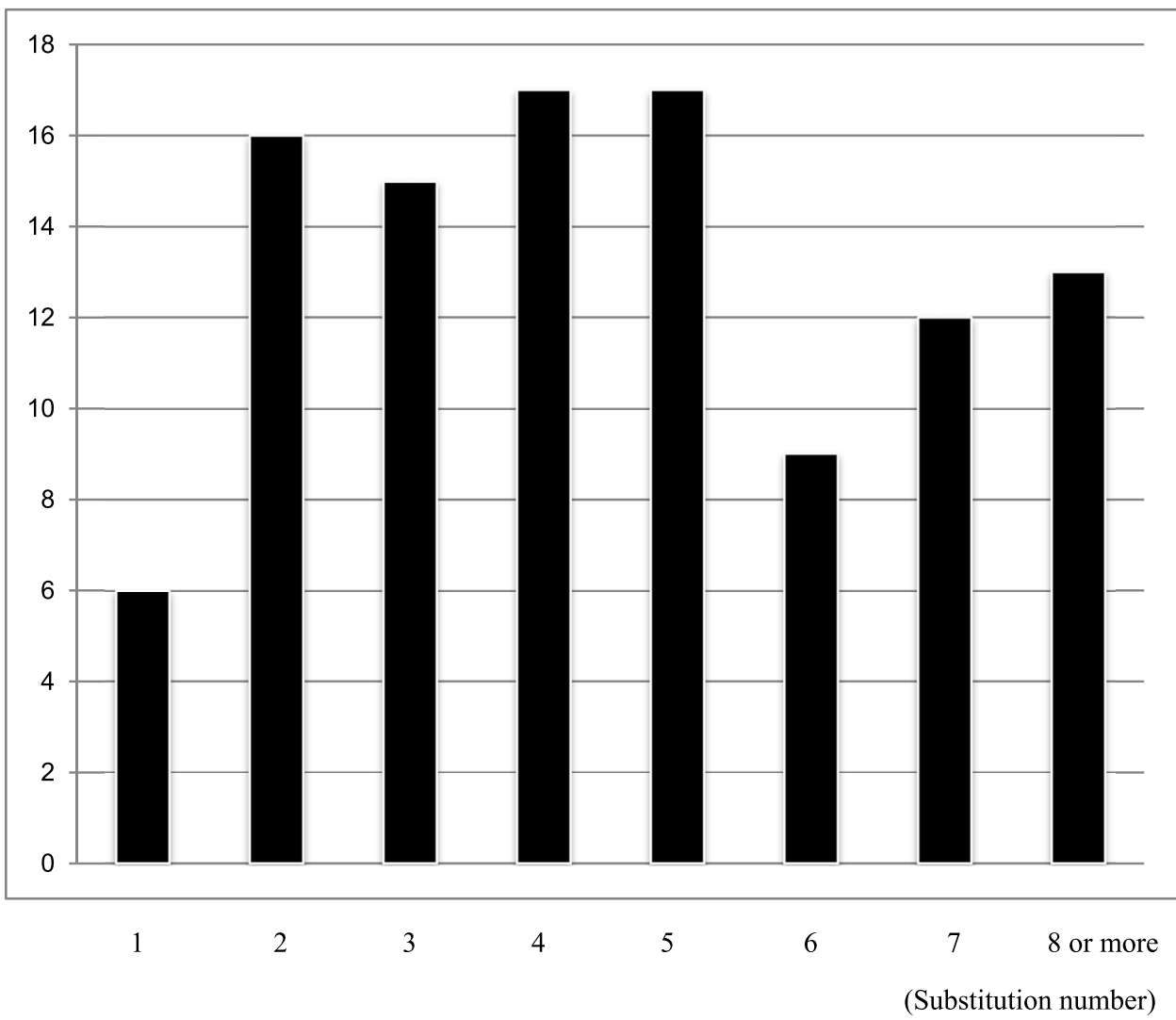

Figure 3. Distribution of aa substitution number in the IRRDR among 105 chronic HCV-G1b patients

\begin{tabular}{|l|l|l|l|}
\hline & Substitutions $(\leq 5)$ & Substitutions $(\geq 6)$ & $P$ value \\
\hline TC & $171(115-253)$ & $160(96-268)$ & 0.10 \\
\hline TG & $81(42-267)$ & $82(37-207)$ & 0.83 \\
\hline LDL-C & $93(36-193)$ & $86(50-172)$ & 0.40 \\
\hline apoB-100 & $75(39-131)$ & $72(44-135)$ & 0.23 \\
\hline IL28-B (TT/nonTT) & $39 / 35$ & $20 / 5$ & 0.024 \\
\hline
\end{tabular}

Data were expressed as median (range)

Table 7. Differences in lipid profile according to the substitution number in the IRRDR

Next, we examined the relationship between each aa substitution in the IRRDR and dyslipoproteinemia. As illustrated in Figure 4, substitution at aa 2356 may impact serum lipid profiles. There was no difference in lipid profile related to substitutions other than aa 2356.

A substitution at aa 2356 from Gly to Glu, Lys or Ala may be critical for distortion of the serum lipid profile. This substitution was previously shown to be a key substitution 
determining virological outcome of PEG-IFN plus RBV therapy in HCV-G1b patients [39]. The therapeutic outcome of 63 patients treated with PEG-IFN plus RBV is indicated in the lower right of Figure 4. Although a clear difference was not observed in the outcome of the therapy, NVR tended to be frequent in patients with non-Gly at aa 2356. The substitution at aa 2356 of Gly to Glu or Gly to Lys caused a drastic change in the nature of the amino acid that may influence the nature of the protein and in turn affect the biochemical interaction of apoE or apoB-100 with NA5A protein resulting in the decrease of serum apoB-100 and LDLC. However, the change in serum apoB-100 level was minor. As aa substitution in the IRRDR is somewhat related to aa substitution in other regions such as the core aa 70, further examination is needed to establish the importance of aa 2356 substitution on lipoprotein metabolism in chronic HCV-G1b infection.

aa2334

aa2379

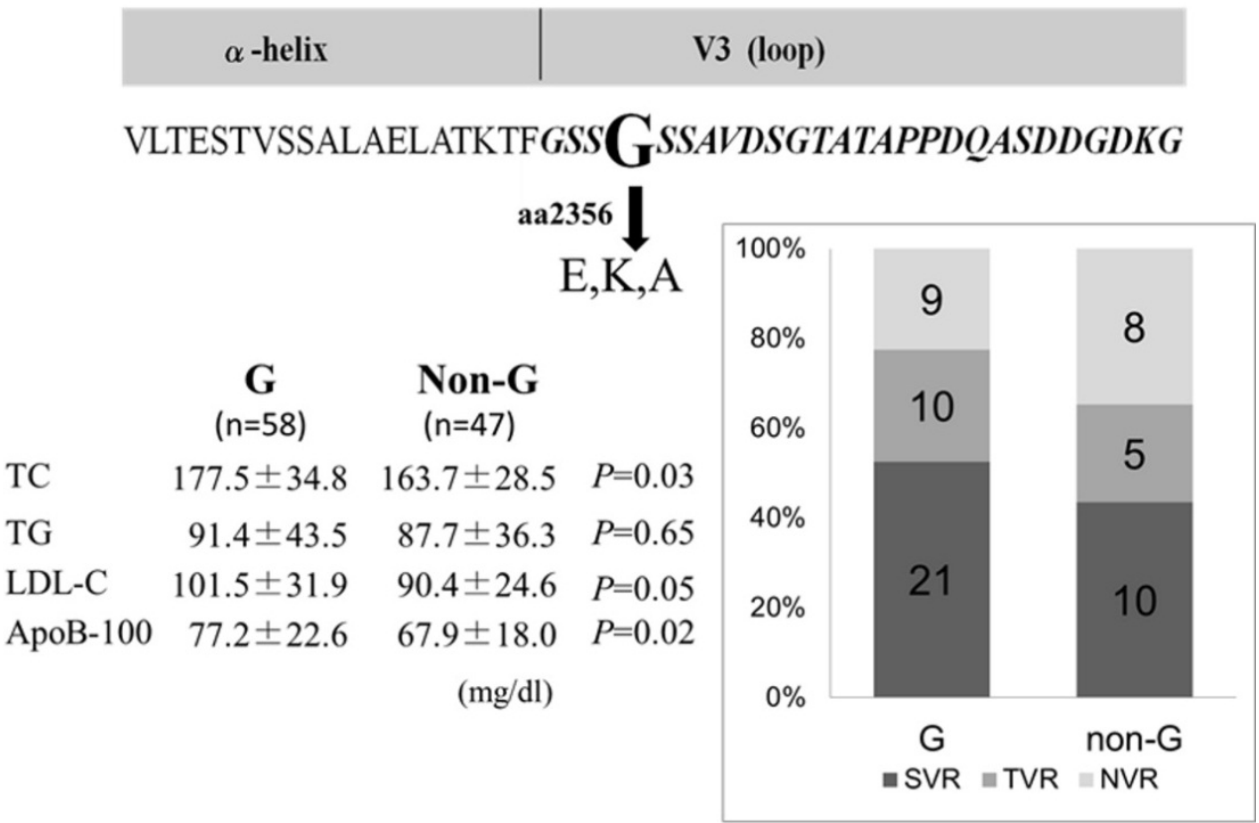

Figure 4. Consequence of substitution at aa 2356 from $\mathrm{G}$ to $\mathrm{E}, \mathrm{K}$ or $\mathrm{A}$ in the IRRDR. Serum levels of TC, LDL-C and apoB-100 were significantly higher in patients who had G2356 than in patients who had not. At lower right, the virological response to PEG-IFN plus RBV therapy in 63 patients with HCV-G1b was summarized.

\section{Are lipid/lipoprotein profiles independent predictors of therapeutic outcome in chronic HCV- G1b infection?}

Chronic HCV infection has been treated with PEG-IFN and RBV combination therapy. $\mathrm{HCV}-\mathrm{G} 2$ and HCV-G3 responded fairly well to this combination therapy. However, the response was weaker in HCV-G1 patients with only half of the patients achieving a 
sustained virological response. Before the discovery of the IL28B genotype, a decrease in TC, LDL-cholesterol or apoB-100-related cholesterol had been considered as an independent predictor of the outcome of PEG-IFN plus RBV therapy in HCV-G1. However, after the discovery that the genotype near the IL28B gene was a potent predictor, serum lipid levels have since been considered to be a confounding factor of the IL28B genotype. Actually, as we described earlier in this chapter and also in an earlier manuscript [36], the IL28B genotype may profoundly affect serum lipid levels in HCV-G1b infection.

Our latest knowledge, based on a prospective study examining predictive factors for the outcome of PEG-IFN plus RBV therapy, indicates that an increase in serum apoB-100 levels is an independent factor predicting rapid virological response (decline of serum HCV RNA at 4 weeks) to PEG-IFN plus RBV therapy. However, it does not appear to be an independent predictor of the final outcome of virological response in chronic HCV-G1b infection (data currently under consideration for contribution). These findings may partly indicate that disturbance of the lipid profile may reflect the efficiency of HCV replication due to efficient entry of HCV into hepatic cells and efficient production/secretion of HCV along with VLDL.

Although the evidence described in this chapter is not based on in vitro studies using HCVsecreting cells, our observations based on clinical samples may contribute to furthering the understanding of HCV-lipid metabolism interaction. From this viewpoint, it is noteworthy that lipoprotein lipase may act not only in the conversion of VLDL to LDL, but also in inhibiting HCV entry into liver cells [23]. Interestingly, in in vitro studies using naturally $\mathrm{HCV}$-secreting cells, the enzymatic activity of lipoprotein lipase may be reduced in HCVinfected cells and may act to promote cell entry of HCV. This may contribute to an increase in the number of large-size (suitable for VLDL particle size) LVP having a chemical nature of LDL as suggested in our HPLC-based study.

Finally, hepatic steatosis may be associated with dyslipoproteinemia in chronic HCV infection and has been extensively studied with special attention to its relation to the IL28B genotype [40] and substitution at aa 70 [17] in HCV-G1b. However, in our experience, the relationship between hepatic steatosis and these host and/or viral factors was equivocal, perhaps because there are other environmental and host factors strongly affecting hepatic steatosis other than the factors discussed in this manuscript.

\section{Summary}

The features of dyslipoproteinemia in chronic HCV infection have been described. Serum lipid/lipoprotein profiles were in part HCV-genotype specific. The HCV core protein of HCVG1b is closely associated with lipoprotein metabolism, and substitution of amino acid (aa 70) in the core protein may precipitate dyslipoproteinemia, in addition to substitution of aa 2356 in NS5A. In addition, dyslipoproteinemia in chronic HCV-G1b infection is largely affected by the genotype near the human IL28B gene. Therefore, dyslipoproteinemia in chronic HCV infection may involve complicated interplay between viral and host factors that could affect human lipid metabolism. Further study of lipids/lipoproteins in chronic HCV infection will be valuable to clarify the interaction of $\mathrm{HCV}$ and host lipid metabolism in detail. Dyslipoproteinemia in chronic HCV-G1b infection may play a role in the rapid decline of HCV 
during PEG-IFN plus RBV therapy. However, the clinical utility of dyslipoproteinemia as a predictor of final response to PEG-IFN plus RBV treatment remains controversial.

\section{Author details}

Yoshio Aizawa*, Hiroshi Abe, Kai Yoshizawa, Haruya Ishiguro and Yuta Aida Jikei University Katsushika Medical Center, Division of Gastroenterology and Hepatology, Internal Medicine, Aoto, Katsushika-ku, Tokyo, Japan

Noritomo Shimada

Shinmatsudo Chuo General Hospital, Department of Gastroenterology and Hepatology, Shin-Matsudo, Matsudo City, Chiba, Japan

Akihito Tsubota

Jikei University Kashiwa Hospital, Institute of Clinical Medicine and Research (ICMR), Kashiwa City, Chiba, Japan

\section{Acknowledgement}

We thank professor Enomoto and doctor Maekawa, University of Yamanashi for kind examination of aa substitution within IRRDR.

\section{References}

[1] Target-Adams P, Boulant s, Douglas MW, McLauchlan J. (2010) Lipid metabolism and HCV infection. Viruses 2: 1195-1217.

[2] Syed GH, Amako Y, Siddqui A. (2010) Hepatitis C virus hijacks host lipid metabolism. Trends Endocrinol Metab 21:33-40.

[3] Popescu CI, Dubuisson J. (2009) Role of lipid metabolism in hepatitis C virus assembly and entry. Biol Cell 102:63-74

[4] Alvisi G, Madan V, Bartenschlager R. (2011) Hepatitis C virus and host cell lipids: an intimate connection. RNA Biol 8:258-269.

[5] Gastaminza P, Cheng G, Wieland S, Zhong J, Liao W et al. (2008) Cellular determinants of hepatitis C virus assembly, maturation, degradation and secretion. J Virol 82:21202129.

[6] Huang H, Sun F, Owen DM, Li W, Chen Y et al. (2007) Hepatitis C virus production by human hepatocytes dependent on assembly and secretion of very low-density lipoproteins. Proc Natl Acad Sci USA 104:5848-5853.

[7] Sabahi A, Marsh KA, Dahari H, Corcoran P, Lamora JM et al. (2010) The rate of hepatitis $C$ virus infection initiation in vitro is directly related to particle density. Virology 407:110-119.

\footnotetext{
${ }^{*}$ Corresponding Author
} 
[8] Nielsen SU, Bassendine MF, Burt AD, Martin C, Pumeechockchai W et al. (2006) Association between hepatitis $C$ virus and very-low-density lipoprotein (VLDL)/LDL analyzed in iodixanol density gradients. J Virol 80:2418-2428.

[9] Popescu CI, Dubuisson J. (2010) Role of lipid metabolism in hepatitis C virus assembly and entry. Biol cell 102:63-74.

[10] Chang K.S, Jiang J, Cai Z, Luo G (2007) Human apolipoprotein e is required for infectivity and production of hepatitis $C$ in cell culture. J Virol 81:13783-13793

[11] Zampino R, Ingrosso D, Durante-Mangoni E, Capasso R, Tripodi MF et al. (2008) Microsomal triglyceride transfer protein (MTP) $-493 \mathrm{G} / \mathrm{T}$ gene polymorphism contributes to fat liver accumulation in HCV genotype 3 infected patients. J Viral Hepat 15:740-746

[12] Domitrovich AM, Felmlee DJ, Siddiqui A. (2005) Hepatitis C nonstructural proteins inhibit apolipoprotein B100 secretion. J Biol Chem 280:39802-39808.

[13] Counihan NA, Rawlinson SM, Lindenbach BD. (2011) Trafficking of hepatitis C virus core protein during virus particle assembly. PLoS Pathog 7: e1002302.

[14] Roingeard P, Depla M. (2011) The birth and life of lipid droplets: learning from the hepatitis C virus. Biol Cell 103:223-231.

[15] Koike K, Tsutsumi T, Yotsuyanagi H, Moriya K. (2010) Lipid metabolism and liver disease in hepatitis $C$ viral infection. Oncology 78 Suppl 1:24-30.

[16] Hourioux C, Patient R, Morin A, Blanchard E, Moreau A et al. (2007) The genotype 3specific hepatitis $C$ virus core protein residue phenylalanine 164 increases steatosis in an in vitro cellular model. Gut 56:1302-1308.

[17] Sumida Y, Kanemasa K, Hara T, Inada Y, Sakai K et al. (2011) Impact of amino acid substitutions in hepatitis $C$ virus genotype $1 \mathrm{~b}$ core region on liver steatosis and glucose tolerance in non-cirrhotic patients without overt diabetes. J Gastroenterol Hepatol 26:836-842.

[18] André P, Komurian-Pradel F, Deforges S, Perret M, Berland JL et al. (2002) Characterization of low- and very-low-density hepatitis C virus RNA-containing particles. J Virol 76:6919-6928.

[19] Napolitano M, Giuliani A, Alonzi T, Mancone C, D'Offizi G et al. (2007) Very low density lipoprotein and low density lipoprotein isolated from patients with hepatitis $\mathrm{C}$ infection induce altered cellular lipid metabolism. J Med Virol 79:254-258.

[20] Meredith LW, Wilson GK, Fletcher NF, McKeating JA. (2012) Hepatitis C virus entry: beyond receptors. Rev Med Virol doi: 10.1002/rmv.723.

[21] Dao Thi VL, Dreux M, Cosset FL. (2011) Scavenger receptor class B type I and the hypervariable region- 1 of hepatitis $C$ virus in cell entry and neutralisation. Expert Rev Mol Med 13:e13.

[22] Sainz Jr B, Barretto N, Martin DN, Hiraga N, Imamura M et al. (2012) Identification of the Nieman-Pick C1-like 1 cholesterol absorption receptor as a new hepatitis $\mathrm{C}$ virus entry factor. Nature Med doi:10,1038/nm.2581.

[23] Maillard P, Walic M, Meuleman P, Roohvand F, Huby T et al. (2011) Lipoprotein lipase inhibits hepatitis $\mathrm{C}$ virus (HCV) infection by blocking virus cell entry. PLoS One 6:e26637. 
[24] Sheridan DA, Price DA, Schmid ML, Toms GL, Donaldson P et al. (2009) Apolipoprotein B-associated cholesterol is a determinant of treatment outcome in patients with chronic hepatitis $C$ virus infection receiving anti-viral agents interferonalpha and ribavirin. Aliment Pharmacol Ther 29:1282-1290.

[25] Moriya K, Shintani Y, Fujie H, Miyoshi H, Tsutsumi T et al. (2003) Serum lipid profile of patients with genotype $1 \mathrm{~b}$ hepatitis $C$ viral infection in Japan. Hepatol Res 25:371-376.

[26] Akuta N, Suzuki F, Kawamura Y, Yatsuji H, Sezaki H ET AL. (2007) Predictors of viral kinetics to peginterferon plus ribavirin combination therapy in Japanese patients infected with hepatitis C virus genotype 1b. J Med Virol 79:1686-1695.

[27] Ramcharran D, Wahed AS, Conjeevaram HS, Evans RW, Wang T et al. (2010) Association between serum lipids and hepatitis $C$ antiviral treatment efficacy. Hepatology 52:854-863.

[28] Li JH, Lao XQ, Tillmann HL, Rowell J, Patel K et al. (2010) Interferon-lambda genotype and low-density lipoprotein cholesterol levels in patients with chronic hepatitis C infection. Hepatology 51:1904-1911.

[29] Kinoshita M, Kojima M, Matsushima T, Teramoto $T$ (2005) Determination of apolipoprotein B-48 in serum by a sandwich ELISA. Clin Chim Acta 351:115-120.

[30] Usui S, Hara S, Hosaki S, Okazaki M. (2002) A new on-line dual enzymatic method for simultaneous quantification of cholesterol and triglycerides in lipoproteins by HPLC. J Lipid Res 43: 805-814.

[31] Okazaki M, Usui S, Ishigami M, Sasaki N, Nakamura T et al. (2005) Identification of Unique Lipoprotein Subclasses for Visceral Obesity by Component Analysis of Cholesterol Profile in High-Performance Liquid Chromatography. S

[32] Akuta N, Suzuki F, Kawamura Y, Yatsuji H, Sezaki H et al. (2007) Predictive factors of early and sustained responses to peginterferon plus ribavirin combination therapy in Japanese patients infected with hepatitis $C$ virus genotype $1 \mathrm{~b}$ : amino acid substitutions in the core region and low-density lipoprotein cholesterol levels. J Hepatol 46:403-410.

[33] Enomoto N, Sakuma I, Asahina Y, Kurosaki M, Murakami T et al. Mutations in the nonstructural protein $5 \mathrm{~A}$ gene and response to interferon in patients with chronic hepatitis C virus 1b infection. (1996) N Engl J Med 1996; 334: 77-81.

[34] El-Shamy A, Nagano-Fujii M, Sasase N, Imoto S, Kim SR et al. (2008) Sequence variation in hepatitis $C$ virus nonstructural protein $5 \mathrm{~A}$ predicts clinical outcome on pegylated interferon/ribavirin combination therapy. Hepatology 48: 38-47.

[35] Sheridan DA, Bridge SH, Felmlee DJ, Crossey MM, Thomas HC et al. (2012) Apolipoprotein-E and hepatitis $C$ lipoviral particles in genotype 1 infection: Evidence for an association with interferon sensitivity. J Hepatol Mar 10. [Epub ahead of print]

[36] Aizawa Y, Yoshizawa K, Aida Y, Ishiguro H, Abe H et al. (2012) Genotype rs8099917 near the IL28B gene and amino acid substitution at position 70 in the core region of the hepatitis C virus are determinants of serum apolipoprotein B-100 concentration in chronic hepatitis C. Mol Cell Biochem 360:9-14.

[37] Mawatari H, Yoneda M, Fujita K, Nozaki Y, Shinohara Y et al. (2010) Association between lipoprotein subfraction profile and the response to hepatitis $\mathrm{C}$ treatment in Japanese patients with genotype 1b. J Virol Hepatitis 17:274-279. 
[38] ElHefnawi MM, Zada S, El-Azab IA. (2010) Prediction of prognostic biomarkers for interferon-based therapy to hepatitis $C$ virus patients: a meta-analysis of the NS5A protein in subtypes $1 \mathrm{a}, 1 \mathrm{~b}$, and 3a. Virol J Jun 15;7:130.

[39] Ohnishi M, Tsuge M, Kohno T, Zhang Y, Abe H et al. (2012) IL28B polymorphism is associated with fatty change in the liver of chronic hepatitis $\mathrm{C}$ patients. J Gastroenterol. 2012 Feb 18. [Epub ahead of print]. 